\title{
IDENTIDAD Y GESTIÓN COMUNITARIA DEL TERRITORIO EN UN EJIDO DE GUANAJUATO, MÉXICO
}

\author{
Davison G. MAZABEL ${ }^{1}$; Gloria A. MIRANDA² ${ }^{2}$ Ínigo GONZÁLEZ-FUENTE ${ }^{3}$ \\ Instituto Michoacano de Ciencias de la Educación ${ }^{1}$; Universidad de Guanajuato ${ }^{2}$; \\ Universidad de Cantabria ${ }^{3}$ \\ dmazabel@gmail.com, mirandazambrano.gloria@yahoo.com.mx, inigo.gonzalez@unican.es
}

\section{IDENTITY AND COMMUNITY MANAGEMENT OF LAND IN A RURAL AREA OF GUANAJUATO, MEXICO}

Resumen: Este trabajo describe y analiza los procesos de construcción social del lugar en un ejido mexicano localizado en el Bajío Guanajuatense, en donde los procesos de apropiación del territorio en consonancia con los ajustes de la identidad social han favorecido la autogestión del territorio y la defensa y conservación de los recursos: agua, tierra y biodiversidad.

Abstract: This paper describes and analyzes the processes of social construction of place in a Mexican ejido located in the Bajio Guanajuatense, where the processes of appropriation of the territory in line with the settings of social identity have favored self-management of the territory and the protection and conservation of resources: water, land and biodiversity.

Palabras clave: Apropiación del espacio. Identidad social. Resistencia comunitaria. Sustentabilidad Appropriation of space. Social identity. Community resistance. Sustainability 


\section{Introducción}

El ejido Ojo de Agua de Ballesteros (Guanajuato, México) constituye uno de los casos más representativos y sui generis de la región. Caracterizado por una abundante y compleja biodiversidad natural, y una administración centrada en el lugar articulada a componentes socio-culturales de tipo campesino, enfrenta la pérdida y amenaza cotidiana de despojo y descalabro de sus capitales por actores sociales y políticos externos.

Dicho contexto amenazante podría erosionar los conocimientos, habilidades y destrezas en la gestión colectiva de los recursos y el territorio, fenómeno que se explica cuando hay una línea fina que anuncia que existe una relación alarmante entre la erosión cultural y la erosión de los recursos naturales. Empero, la resistencia por el agua, tierra y biodiversidad es una apuesta que sus actores sociales se han trazado y vienen enfrentando al gestionar -entre otras acciones de defensa y empoderamiento-, el "Balneario Ejidal", empresa social que como proyecto de soporte institucional, es el eje articulador de las acciones de administración de los recursos tanto naturales como sociales. En torno a él, a su manantial, se han elaborado importantes representaciones sociales, se han realizado acciones concretas y es un nodo de identificación simbólica para los ejidatarios.

Casos como el protagonismo del ejido Ojo de Agua de Ballesteros conviene vigorizar en la medida que es una de las crecientes experiencias esperanzadoras con enfoque alternativo, en el objetivo de poner en práctica la propuesta conciliadora ecología-economía en aras de revitalizar la sustentabilidad per se campesina en la amenazante arena de la mundialización neoliberal.

En este contexto, el objetivo del presente estudio es analizar y comprender el proceso de la construcción social de lugar en el ejido Ojo de Agua de Ballesteros, partiendo de la consideración del espacio simbólico, la identidad social y el apego al lugar como principales conceptos. Los autores parten de la hipótesis de que es la apropiación del espacio en correspondencia con los reajustes de la identidad social lo que, en el caso de este ejido, permite la posibilidad de entablar una relación directa con el territorio ${ }^{1}$-sobre el que se ejerce una territorialidad ${ }^{2}-\mathrm{y}$ en el que la gestión de los recursos tiene como referente componentes socio-culturales. A modo de conclusión, los autores valoran los alcances de cierto tipo de apropiación colectiva ${ }^{3}$ del territorio en términos de la sustentabilidad, es decir entender de qué manera los procesos de autogestión centrados en el lugar promueven escenarios de sustentabilidad.

\section{Diseño metodológico}

Ojo de Agua de Ballesteros se encuentra en el municipio de Salvatierra, Guanajuato, a $1,760 \mathrm{msnm}$. Se localiza en el área centro-oriental del municipio y colinda con las localidades de El Fenix y Urireo (Salvatierra), así como con el municipio de Tarimoro. Se encuentra en una zona de laderas, articulada al sistema montañoso conocido como Picacho o Cuevas de Moreno.

La metodología empleada fue de tipo etnográfico. El trabajo de campo se realizó durante varias visitas realizadas durante 2009 y 2010 y se contrastó con las observaciones e información recogida durante el primer semestre de 2013.Se aplicaron entrevistas abiertas y semiestructuradas con miembros de la comunidad, así como con población de localidades

1 En el que se vive el sentido de lugar, sobre el que se actúa y significa, es decir se le asigna el carácter de un espacio apropiado, asumido para sí y sobre el que se decide, esto es, desde la perspectiva de la colectividad.

2 Entendemos la territorialidad como "el intento de un individuo o grupo de afectar, influir o controlar gente, elementos y sus relaciones, delimitando y ejerciendo un control sobre un área geográfica" (Sack, 1991: 94).

3 Con orientación comunitaria, basada en la cultura local. 


\section{Localización geográfica}

Fuente: googlemaps (14/04/2013).

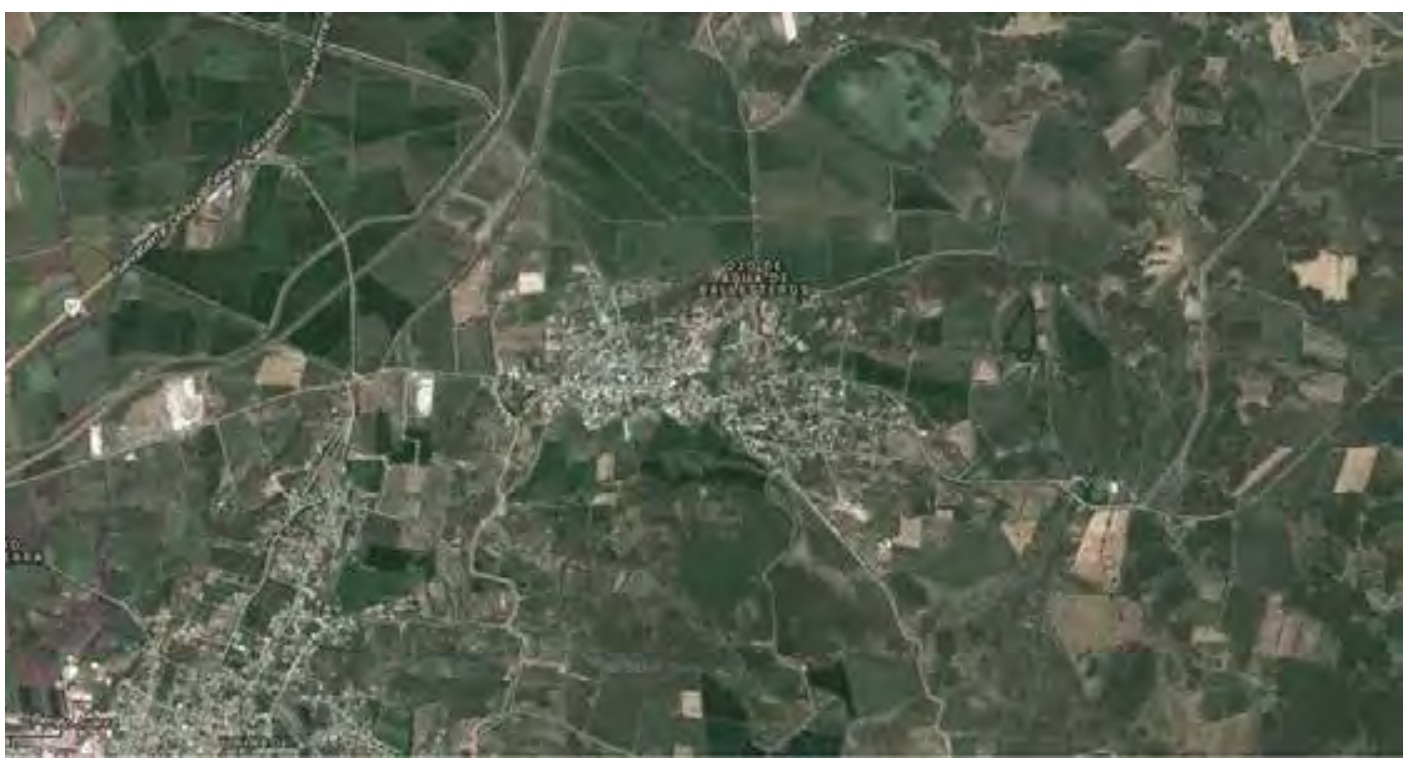

cercanas; con los ejidatarios se realizaron entrevistas que combinaron la inducción analítica-conversacional y los relatos de vida.

La recopilación de carácter histórico se basó principalmente en la historia oral, aunque también se consultaron acervos documentales.

\section{Marco teórico-referencial}

El concepto de apropiación del que aquí se parte se basa en el modelo dual de la apropiación propuesto por Pol (1996, 2002a), y que se resume en dos ejes principales: la accióntransformación y la identificación simbólica. La primera se articula con la territorialidad y el espacio personal en la perspectiva de Altman (1975), lo que también es sostenido por Brower (1980) al considerar la apropiación como un concepto "subsidiario" de la territorialidad. Por otro lado, la identificación simbólica se vincula con procesos afectivos, cognitivos e interactivos.

A través de las acciones sobre el entorno, no sólo se transforma el espacio sobre el que se vive, sino que además se dejan huellas o marcas sobre él que pueden tener connotaciones simbólicas, lo que de alguna manera es una forma de ejercer la territorialidad, al tiempo que promueve el sentido de pertenencia.

Cuando se da o mantiene un proceso de interacción con el entorno y los seres que lo habitan -incluidas las personas- de manera situada o territorializada, el espacio apropiado es considerado un factor de continuidad y de estabilidad de la identidad y la cohesión del grupo o colectividad.

Como lo ha señalado Pol (2002b), la apropiación del espacio es una forma de entender la generación de los vínculos con los "lugares", lo que facilita comportamientos ecológicamente responsables, y la implicación y la participación en el propio entorno.

"Entendido de esta forma, el entorno "apropiado" deviene y desarrolla un papel fundamental en los procesos cognitivos (conocimiento, categorización, orientación, etc.), afectivos (atracción del lugar, autoestima, etc.), de identidad y relacionales (implicación y corresponsabilización). Es decir, el entorno 
explica dimensiones del comportamiento más allá de lo que es meramente funcional" (Vidal y Pol, 2005: 284).

Es precisamente con esta conceptualización de donde partimos para comprender y analizar escenarios de sustentabilidad y de gestión colectiva del territorio y sus recursos.

\section{La importancia de la identidad}

Cuando nos referimos a la identidad social de los ejidatarios de Ojo de Agua de Ballesteros, hacemos alusión al conjunto de relaciones sociales implicadas en el proceso constituyente de dicha identidad y, en consecuencia, a las sucesivas transformaciones que la han caracterizado hasta la actualidad.

Estas transformaciones incluyen desde que eran campesinos temporaleros -con antecedentes indígenas-, hasta que llegaron a ser ejidatarios como tales y practicantes de la agricultura de riego. Durante este tiempo, los ahora ejidatarios ocuparon diversos nichos ecológicos conforme a las características físico-geográficas: peones acasillados, trabajadores agrícolas de haciendas de la zona, jornaleros agrícolas, demandantes de tierra, "ocupantes" de la misma, etcétera. Este contexto, a su vez, implica considerar las relaciones sociales presentes en la construcción histórica del espacio social, en una región con vocación agrícola circundada por el Distrito de Riego 011, pero al que los ejidatarios de Ojo de Agua de Ballesteros no pertenecerían de manera formal, aunque sí prácticamente la totalidad de los ejidos vecinos y la mayor parte de los ejidos del Bajío Guanajuatense. ${ }^{4}$

Es interesante señalar asimismo que la mayor parte de estos espacios han ido asumiendo un carácter crecientemente urbano con diversas influencias del Norte, producto de las sucesivas migraciones a los Estados Unidos y una intensa relación, por la actividad agrícola, con las ciudades medias que se han desarrollado en las cercanías, particularmente sobre el Corredor Industrial ${ }^{5}$.

Si bien el carácter de ser ejidatario en términos de los derechos de los sujetos se desprende de la propia Constitución Política de los Estados Mexicanos y de la Ley Agraria en la que se contiene la propiedad social de la tierra, la articulación de los ejidos deviene de los procesos histórico-sociales que vivieron las diferentes regiones del territorio mexicano, o en otras palabras, de las características de los esquemas organizativos previos, de los procesos de lucha y participación política por la defensa de la tierra y el patrimonio cultural articulado a ella, de los avances o retrocesos soportados o confrontados con el poder regional.

El Estado otorga y concede derechos a su población, en este caso a la tierra como propiedad social y le confiere un carácter, pero es la sociedad, y de manera concreta, las colectividades o comunidades las que le confieren sentidos y prácticas al ejercicio de estos derechos sobre sus territorios, y es precisamente en este punto en el que la apropiación y la identidad social juegan un papel medular en la construcción social de dichos territorios.

En un contexto como el del Bajío, con un intenso poder regional impuesto desde el periodo colonial, centrado en la figura de los hacendados y la Iglesia Católica, al momento del reparto agrario, los patrones de subordinación se reactivaron en esquemas de sujeción,

\footnotetext{
4 Para el caso del agua superficial, tradicionalmente, los ejidos en el municipio de Salvatierra y de la región practican la agricultura de riego fundamentalmente a través de su pertenencia al Distrito de Riego 011, de manera que la gestión e intervención sobre el agua está supeditada a esta estructura. De esta suerte, los procesos políticos y socio-territoriales en torno al recurso se expresan de una manera diferente y están sujetos a la reglamentación y disponibilidad del propio Módulo de Riego de Salvatierra y del Distrito de Riego. No así, en el caso del ejido Ojo de Agua de Ballesteros que presenta matices distintos a los del resto.

5 Situado en el Bajío Mexicano, se encuentra alrededor del principal sistema de carreteras del estado de Guanajuato, conecta las principales ciudades del estado, desde Celaya a León. Alrededor de él se encuentran las zonas industriales y de abastecimiento más importantes del estado y la región, incluida la pujante industria automotriz.
} 
control y lealtades en torno al patrón y a los sacerdotes, de suerte que es frecuente encontrar testimonios sobre la época en prácticamente todos los ejidos de la región sobre las arengas de los curas diciéndole a la gente que si pedían la tierra "se irían al infierno o al purgatorio".

La polarización generada en dicho contexto adquirió matices particulares en cada comunidad, de acuerdo a la participación política o la toma de posición sobre los sucesos que se dieron en la región y el país. En este sentido, también la población de Ojo de Agua de Ballesteros recuerda cuando pasó la caravana de los Villistas por el territorio, destacando con su testimonio su adherencia al proceso revolucionario y sus demandas.

Otro elemento interesante reside en el hecho de que, pese a que el otorgamiento de los derechos como ejidatarios se dio a título individual y privilegió la línea masculina, en la práctica podemos observar, en el caso del ejido de Ballesteros, la impronta de la participación femenina en las actividades y decisiones del ejido y sus recursos. Ello repercute en que, en la cotidianidad, toda la familia usufructúe los derechos de tierra y agua reconocidos nominalmente y, asimismo, refleja también que los ejidatarios vinculan estrechamente su unidad productiva con la vida doméstica y social. Este aspecto que destaca la equidad ampliada, involucra a los miembros de la familia en las acciones que sucesivamente transforman el entorno, propiciando procesos de empoderamiento y apropiación.

La concatenación de las estrategias y los mecanismos de socialización ejercidos al interior del ejido inciden seguramente en el fortalecimiento de la resiliencia, tanto para el caso de los siniestros agrícolas (sequías, granizadas, etc.) como para las cambiantes condiciones experimentadas en el campo mexicano; así, vemos que, como consecuencia de la crisis agrícola que inició a partir de la década de los setenta, se produjo un creciente proceso de expulsión de mano de obra de pobladores de las zonas de riego en la región, sobre todo los ejidatarios y sus hijos. El estrechamiento del mercado de trabajo, la falta de ganancias y un creciente movimiento de la tierra polarizaron aún más las diferencias sociales entre los productores agrícolas, situación que ha sido matizada y amortiguada hasta cierto punto en Ballesteros.

El conjunto de estas situaciones ha tenido varios efectos en los ejidatarios y comunidades de la región, que se expresan en la desestructuración o reestructuración de sus familias, ampliando sus funciones y provocando la emigración de una parte importante de sus miembros hacia EE.UU., hacia diferentes sectores económicos. Esto ha generado en unos la diversificación de la identidad, y en otros la intensificación de procesos de aculturación y de deterioro del tejido social, propiciando con ello lo que Durkheim (1998a, 1998b) denominó anomia social.

Frente a lo anterior, diversas comunidades y ejidos en México han tenido que hacer acopio de sus fortalezas y capacidad creativa para realizar ajustes ${ }^{6}$ en su identidad social e incorporar la multifuncionalidad y sus reservas estratégicas. En muchos casos, las mujeres ocupan los puestos dejados por los hombres en la dirección de la producción agrícola, la familia y la comunidad. En otros casos, los hombres que se quedan, conscientes de la fatalidad de sus vecinos, desarrollan estrategias para darle sentido a su vida y a su actuación sobre su ambiente. Estos reajustes de la identidad social parecen ejercer, como una de sus principales funciones, la inhibición del deterioro de la cultura productiva en la zona. Nos hallamos probablemente, según Fracchia (1997), no ante las tantas veces pronosticada desaparición del ejidatario como identidad social, sino frente a su revitalización.

\section{La dimensión cultural}

Tomando en consideración que la identidad es un constructo social histórico y que, en el caso que aquí se presenta, se articula con los procesos simbólicos implicados en la asunción, acción y transformación del territorio, resulta pertinente entender cómo la dimensión

6 Fracchia (1997) plantea la hipótesis de que se trata de una reestructuración de la identidad social. 
cultural se expresa en un entramado complejo de significaciones imbricado con lo social.

De esta manera, el sistema de significaciones que opera en una cultura es un observable central de esta, y su peculiaridad estriba en que sus términos no poseen en sí mismos una significación intrínseca, sino en que su significación tiene lugar en función de la historia y del contexto cultural así como de la estructura del sistema en el que habrán de figurar (LéviStrauss, 1992: 86-87).

Lévi-Strauss analiza la cultura observándola al interior de sí misma y en su relación con otras, desde una perspectiva de totalidad, recurriendo hasta donde sea posible al pasado, lo que permite que todos los hechos analizados se integren en una totalidad significante y así, pueda ser interiorizada por el sujeto, lo que a su vez lo transforma, permitiéndole percibir otros horizontes y otros objetos (Lévi-Strauss, 1992: 366).

Desde una perspectiva cercana a Lévi Strauss, Bartolomé (1997: 42-43) plantea que la identidad "representa un fenómeno procesual y cambiante, históricamente ligado a contextos específicos [que] alude a fenómenos múltiples". Este autor distingue los procesos culturales de los de producción de identidad señalando que pese a que:

"La identidad colectiva tiende a reflejar las normas culturales de una sociedad, no depende exclusivamente de éstas para existir como tal [...] Las configuraciones identitarias se pueden basar en una filiación cultural propia, o asumida como propia, con independencia de que la tradición cultural vaya cambiando con el transcurso del tiempo" (Bartolomé, 1997: 75).

Para poder integrar los observables de las dimensiones social y cultural de la identidad, hemos tomado en consideración la autopercepción de la identidad por parte de los ejidatarios -así como la de otras identidades con las que se mantienen confrontados y/o con las que conviven en la zona-, en el sentido de observar cuáles de los elementos que definían su identidad de origen se mantienen y cuáles se han transformado. Por ejemplo, tenemos en cuenta los elementos que se derivan de la mayor cantidad de tareas sociales que hoy llevan a cabo los ejidatarios, la interacción con el ambiente, los sentidos en la apropiación del lugar, y su proyecto a futuro.

En suma, es nuestra pretensión comprender los cambios operados en el proceso de conformación de la identidad social, la cual abarca el conjunto de transformaciones históricas de la misma, con las de la propia cultura, es decir: 1. con su visión del mundo, sus áreas de conocimiento y experiencias, sus formas de comunicación, sus prácticas sociales en la familia y en el poblado; 2. con relación a las instituciones que produjeron en el origen la identidad del ejidatario y, 3. en la actualidad, con las nuevas instituciones que implica el desarrollo de sus nuevas funciones (respecto de las originales, como ejidatarios de riego). Sin embargo, esta comprensión no es en un sentido unívoco o unidimensional sino que se trabaja desde una perspectiva compleja y profunda, en este caso, no subordinada sino proactiva y propositiva frente a modalidades de desarrollo verticales y ajenas al territorio.

\section{Antecedentes históricos}

Este trabajo resalta la historia local de los "otros" recolectada a partir de los testimonios que nos proporciona la historia oral. Con ello, es nuestra intención dar un punto de quiebre o de ruptura en el imaginario y las representaciones de un grupo de salvaterrenses que han vivido y visualizado la historia y el presente de Salvatierra a partir de los monumentos religiosos o las casonas de la época colonial que revisten el centro histórico, de las leyendas de la cabecera colonial y el "legado español" en alusión al origen nobiliario de algunas familias. En este sentido, estamos redescubriendo y leyendo e interpretando con otros lentes el pasado y el presente del municipio, y sus territorios, con base en trayectorias histórico- 
culturales que hacen referencia a pueblos originarios. ${ }^{7}$

Resulta sorprendente que, de los registros disponibles en los acervos históricos de la localidad y la región, parece no existir mucha información sobre los antecedentes territoriales de Ojo de Agua de Ballesteros, así como de la mayor parte de las localidades pertenecientes al municipio de Salvatierra. No obstante, en dos registros documentales de la época colonial sobre Salvatierra -aunque de diferentes fechas-, se encuentran referencias sobre este territorio.

Por un lado, en el libro Historia y Evolución de Salvatierra, Miguel Alejo (2010) hace referencia a que en el año de 1535 la primera merced otorgada en el Valle de Huatzindeo (parte del actual municipio de Salvatierra) se concedió en el sitio denominado Ojo de Agua de Ballesteros, durante el gobierno del Virrey Don Antonio de Mendoza.

En el así llamado, de manera local, Libro Prieto ${ }^{8}$ existe otro documento del siglo XVIII, en el que se hace referencia al pueblo y hacienda Ojo de Agua en donde se hace una recomposición de tierras:

“1755 El virrey de la Nueva España, Conde de Revillagigedo, por Real Cedula ordeno la recomposición de la tierras del pueblo y la de la hacienda Ojo de Agua, al juez de comisión Don Juan Fajardo y Babosa” (Libro Prieto, $2^{\circ}$ Tomo).

En cualquier caso, no queda claro, en el caso de las tierras del pueblo, a favor de quién se hizo esta recomposición o en qué sentido. ${ }^{9}$

Dentro de la historia nacional, a partir de 1856 se pone en marcha la Ley Lerdo, la cual abría la posibilidad de desamortizar los bienes o tierras comunales de los indios, por lo que en muchas partes del territorio les son arrebatadas las tierras que correspondían a los nativos.

Con la implementación de esta ley, las tierras de Ojo de Agua pasan a manos del hacendado Fernando López de Ballesteros. No se sabe si antes o a partir de este acontecimiento, se dice, quince familias del lugar denominado la Lagartija deciden quedarse en la hacienda de "Don Fernando" a trabajar como peones. Así se recuerda a través de la memoria colectiva al otrora propietario de la hacienda Ojo de Agua:

El capitán Fernando López de Ballesteros era dueño de toda la tierra que actualmente pertenece al ejido, él estaba en contra de que los campesinos tuvieran un reparto agrario justo, por lo que ellos exigían el reparto agrario suscitado en el periodo Carrancista. Después de varias luchas y como resultado de la revolución (Comunicación personal, 2010).

Es con posterioridad, según narra la historia oral, hasta la revuelta revolucionaria cuando dichas tierras se reintegran a la comunidad. La gente asume su posición como demandantes de tierra haciendo énfasis en la importancia de la marcha Villista y a su apoyo cuando en su paso por la república transita por estas tierras, provenientes del municipio de Celaya.

Para el año de 1931, los habitantes del poblado de Ojo de Agua de Ballesteros solicitaron al C. Gobernador del Estado, la dotación de tierras por carecer de ellas para satisfacer sus

7 En años recientes la población de Ballesteros solicitó ante la Secretaría de Desarrollo Social y Humano del Estado de Guanajuato, ser reconocida como comunidad indígena, al señalar ser descendientes de la etnia otomí. 8 En realidad se trata de una compilación de documentos históricos hecha por Vicente Ruiz Arias, cronista local en su momento.

9 Las composiciones de tierras se realizaban cuando se trataba de tierras en demasías, es decir que no contaban con un título o situación legal definida, era un recurso muy utilizado por los hacendados para legitimar la propiedad adquirida por vías poco claras y al mismo tiempo beneficiaba a la Corona como un mecanismo extraordinario de recaudación. 
necesidades y con base en las leyes agrarias. La solicitud fue turnada a la Comisión Local Agraria en la cual se fundó el expediente respectivo el 11 de diciembre de 1931, habiéndose publicado dicha petición para conocimiento de las partes interesadas en el Periódico Oficial del Gobierno del Estado en el número correspondiente del 7 de febrero de 1932.

Del título de concesión se desprenden datos puntuales de dicho proceso:

"El expediente fue consignado al Departamento Agrario, para hacer un estudio minucioso de las constancias, los documentos y datos que forman el mismo expediente. Llegando al conocimiento de que en el poblado de Ojo de Agua de Ballesteros contaba con una población de 442 habitantes agrupados en 112 familias de las cuales 152 tienen derecho a parcela ejidal" (Título de Concesión).

Habiendo trascurrido cuatro años desde la entrega del expediente al Departamento Agrario, los capacitados fueron dotados de tierra:

"Por Resolución Presidencial, el 31de agosto de 1936, se concedió al poblado de Ojo de Agua de Ballesteros, con una superficie de 948-75 Hs. de finca del mismo nombre, como sigue: 162-20 Hs. de riego y 998-14 Hs. de temporal que se destinaran para formar 90 parcelas, 89 de ellas para igual número de capacitados y la restante para la escuela del lugar y 388-41 Hs. de cerril para usos colectivos de los solicitantes" (Título de Concesión).

Siendo así, como se integra el ejido de Ojo de Agua de Ballesteros, haciendo formal entrega de la dotación al poblado, el Ingeniero Luis López Rodríguez quien declaró en nombre del C. Presidente de los Estados Unidos Mexicanos y en cumplimiento de la resolución presidencial de fecha 24 de junio de 1936, la concesión de tierras. Estas fueron repartidas dando lugar al ejido, el poblado fue nombrado Ojo de Agua de Ballesteros por su antecesor propietario y por contar con manantiales de aguas termales.

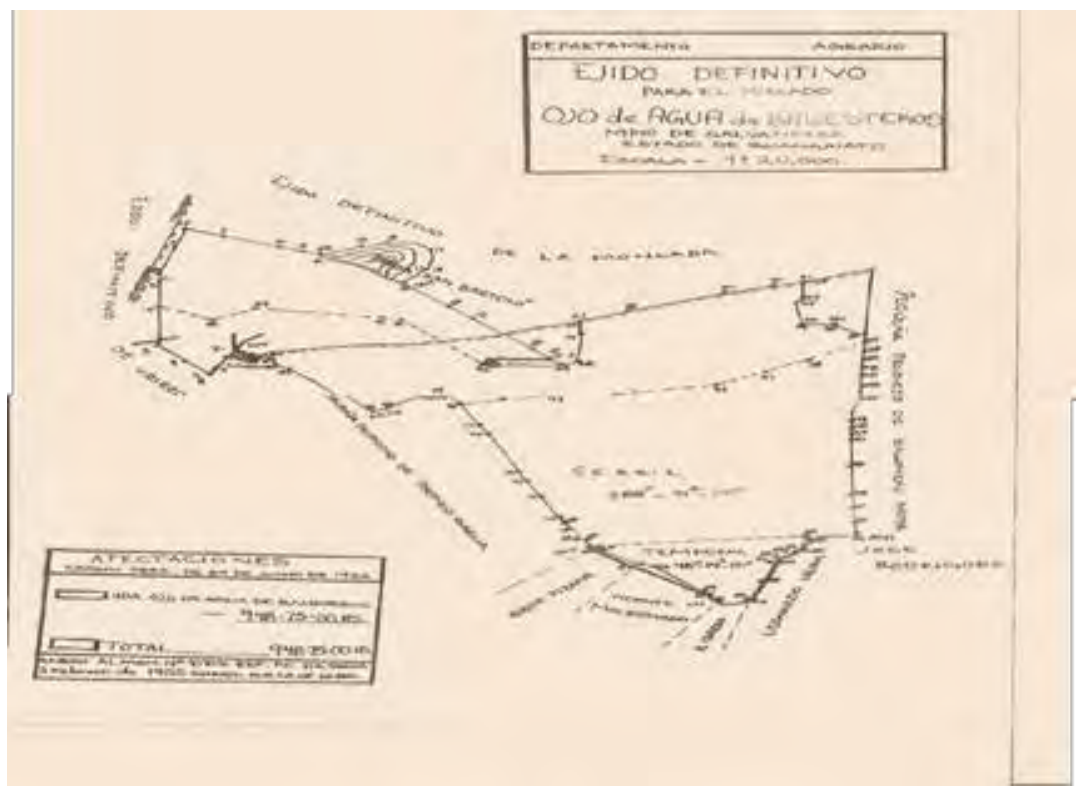

Extensión y límites del Ejido Ojo de Agua de Ballesteros Fuente: Archivo del Ejido, Título de concesión. 


\section{Adscripción étnica y organización social comunitaria}

Es importante señalar que, en términos comunitarios, la gente de Ojo de Agua de Ballesteros se reconoce a sí misma por auto adscripción como comunidad indígena, se asumen como descendientes de la etnia otomí, y que han mantenido sus tradiciones, usos y costumbres por transmisión oral de una generación a otra. Incluso se sostiene que hasta hace poco tiempo se hablaba la lengua materna, pero que poco a poco se ha ido perdiendo.

Se practica el sistema de cargos (existen mayordomías y comités) así como faenas o trabajo colectivo que son realizadas para el bienestar y seguridad de la comunidad. Tienen como algunos de sus lugares sagrados el templo y el ojo de agua, de donde podemos colegir o tener la certeza de la particular importancia y significación del agua para los ejidatarios y en general para la comunidad.

Dicen provenir de un pueblo desaparecido denominado La Lagartija que se encontraba cerca del actual Ballesteros y que el nombre actual de la comunidad proviene del hecho de que en su territorio brotan diferentes fuentes de agua (manantiales) y al apellido del que fuera propietario de la hacienda que existió en ese lugar.

La organización formal del ejido Ojo de Agua de Ballesteros está compuesta por la asamblea general, el comisariado ejidal y el consejo de vigilancia. La máxima autoridad dentro del ejido es la asamblea general, la cual se reúne en sesiones ordinarias y extraordinarias.

El Comisariado Ejidal está compuesto por el presidente, el secretario y el tesorero con sus respectivos suplentes. El comisariado es el representante del ejido y el órgano ejecutivo de las decisiones de la asamblea general. Su presidente tiene funciones de representante, administrador vigilante y apoderado del ejido.

El Consejo de vigilancia está integrado por tres miembros y sus funciones son las de vigilar el buen desempeño del comisariado ejidal y del cumplimiento de los acuerdos en la asamblea general de ejidatarios.

\section{Por la autodeterminación territorial y agraria}

El Programa de Certificación de Derechos Ejidales y Titulación de Solares (PROCEDE) es un instrumento que el Gobierno Federal puso al servicio de los núcleos agrarios en 1992 para llevar a cabo la regularización de la propiedad social. Su objetivo fue brindar certidumbre jurídica a la tenencia de la tierra a través de la entrega de certificados parcelarios o certificados de derechos de uso común, o ambos según sea el caso, así como de los títulos de solares en favor de los individuos con derechos que integran los núcleos agrarios que así lo aprueben y soliciten. Se desarrolla en el marco normativo de la reforma al Artículo 27 Constitucional y de la promulgación de la Ley Agraria y su Reglamento en Materia de Certificación de Derechos Ejidales y Titulación de Solares, así como de las Normas Técnicas para la Delimitación de las Tierras al Interior de Ejido (SRA, 2006). Si bien se desactivó en el 2006, ahora el Fondo de Apoyo para los Núcleos Agrarios sin Regularizar (FANAR) presupone en esencia la misma propuesta a comunidades y ejidos.

En estas circunstancias, los ejidatarios de Ojo de Agua de Ballesteros han enfrentado el asedio frecuente del Programa, declarando con orgullo y dignidad no haber aceptado tal exhortación y seguir según la forma y norma tradicional del trabajo con la tierra de manera colectiva, solidaria y unida como lo ha sido desde su creación.

Evitar el virtual desmantelamiento y consiguiente parcelación de la propiedad comunal, le da el reconocimiento de ser "el único ejido y pueblo originario de la región que no aceptó ingresar al Programa". La férrea resistencia al constante asedio y presión invariable de los representantes de la oficialidad es su mérito.

A continuación se presentan algunos de los testimonios expresados por los ejidatarios en torno a la certificación y a la intervención de los representantes del Procede en el territorio: 
Vienen siquiera una vez al mes y nos preguntan ya hemos acordado en asamblea entrar a su programa. Esos carajos no se cansan, vienen después que hemos tenido asamblea, nos prometen, nos ruegan para hacerles caso. 'Si no entran se acabará el plazo, entonces van a gastar mucho dinero titulándose, nos dicen'. 'Ya pueden construir, y hasta vender si quieren. Sus hijos están asegurados porque ya tienen sus títulos, en cambio ustedes van a dejarles problemas (Comunicación personal, 2010).

Estamos entre la espada y la pared, a cada uno de nosotros -60 ejidatariosmás o menos nos titularían 16 y media hectáreas, con cerro, piedras, monte y demás, pero no lo haremos... unidos estamos mejor. Cómo unos pocos van a tener más agua, más tierra agrícola, el reparto sería a la suerte y no todos tendríamos por igual! (Comunicación personal, 2010).

La tesitura de presión y acecho al patrimonio natural como fenómeno social provocado por las externalidades es complejo, una de las manifestaciones de impacto colectivo es el haber provocado el rozamiento continuo al interior del ejido:

Creen que por cansancio vamos aceptar, claro que nos confunden, nos hacen enfrentar entre nosotros, entre familias ya nos peleamos, algunos ya quieren vender! (Comunicación personal, 2010).

Hay gente que quiere entrar al Procede. El gobierno le da título a cada uno. Yo no tengo nada especificado. Así están todos los papeles. Los más estudiados dicen que no entremos al Procede, los que no afirman que sí, a veces de tanta insistencia y cansancio y para no pelearnos queremos aprobarlo en Asamblea, luego reaccionamos pensando en todo lo que lucharon nuestro padres, y luego, luego nos arrepentimos y nos volvemos mas unidos! (Comunicación personal, 2010).

Yo quiero entrar al Procede. El gobierno le da el título a cada uno. Me favorece porque no tengo nada especificado. Sólo les dejare pleito entre mis hijos cuando me vaya. Por ejemplo, mi papá me dejo un terrero porque era su voluntad y por ello mi hermano ya no me habla hace 20 años. Pero mi hermano se quedó con el título de mi padre. Sin embargo yo sigo produciendo en mi tierra. Por eso para no dejar pleitos, es mejor dejar titulados a los hijos. El gobierno nos va a orillar a aceptar de todas maneras. Actualmente no piden dinero, pero más adelante sí para titularnos, entonces va a ser más difícil! (Comunicación personal, 2010).

Sin embargo, la corriente de enfrentamiento al interior no ha prosperado, la lectura que hacen estos actores del hinterland de los pueblos que ingresaron al Procede, los desalienta, los mueve. La Moncada, San Juan, El Fénix y otros pueblos muestran un rostro adverso:

(Los otros ejidos) están 'hechos guerra' porque están repartidos en pedazos o retaceados en media, un cuarto o un octavo de hectárea. Unos producen y otros ya dejaron las tierras. El Procede los tituló y acabó con el ejido. Eso no queremos, resistiremos hasta el final, no sabemos cómo va acabar esto! (Comunicación personal, 2010).

El panorama de incertidumbre provocado por las externalidades se agudiza cuando al 
acercarse a las convocatorias de los programas oficiales de asistencia al campo, sufren continuo rechazo o restricciones:

Lo primero que nos preguntan es si ya estamos en el Procede, al decirlo que no, ya ni nos reciben nuestros papeles, o nos piden más cosas y ya nos desanimamos. En cambio para los que están en esa institución del gobierno si hay todo tipo de apoyos. (Comunicación personal, 2010).

La lectura podría ser el sentimiento de desunión, de enfrentamiento y división al interior del ejido. La pregunta de rigor sería entonces ¿está amenazada la identidad individual y colectiva?, ¿se estaría entrando a la desestructuración del sentido comunal que enarbola este ejido?

No es nada fácil mantenerse en dos frentes. Por un lado, el interés por resolver las expectativas particulares y, por otro, la defensa del patrimonio social y natural. Pareciera que el sistema no cesa de hacerlos trastabillar; sin embargo, regirse bajo términos de propiedad privada, es lo que menos quiere Ballesteros, por ello siguen en la lucha colectiva, anunciando a la sociedad -como bien señala Melucci (1999)- que existe un problema fundamental en un área dada. Asumen una creciente función simbólica, e incluso podría hablarse de una función profética. No luchan por bienes materiales en sentido estricto o para aumentar su participación en el sistema. Luchan por un proyecto simbólico y cultural, por un significado y una orientación diferentes de acción social. Saben que el territorio, siendo compartido, también son compartidos los agravios y la resistencia. De ahí que el colectivo no hace sino reafirmar que no ingresarán a las cláusulas del Procede. Sin lugar a dudas, la tierra sigue siendo adjetivada como un territorio base de las identidades, principio de la organización social de las unidades familiares y de la comunidad rural y fundamento de la soberanía (Concheiro, 1995). Por ello la mayoría revela:

No lo haremos cueste lo que cueste, 'si es posible daremos nuestra propia vida, y no tenemos miedo al decirlo’. Tenemos que conservar la tierra! (Comunicación personal, 2010).

Los testimonios no hacen sino expresar que las luchas sociales derivan en re-definiciones identitarias que a la vez redefinen territorios, adscripciones y pertenencias a las colectividades. Más aún, el poder, no sólo reprime, sino que también, produce efectos de verdad y produce saber (Foucault, 1998).

Apoyándonos en Melucci (1999) en el concepto de identidad colectiva (teoría de la acción colectiva), Ballesteros estaría desarrollando un conjunto de prácticas sociales que involucran simultáneamente cierto número de individuos y grupos, comparten características similares en el tiempo y espacio y, se relacionan bajo un ideal colectivo, por lo cual mantienen un mismo fin, medios y campo de acción. Pero esa identidad no es producto de la nada, resulta del fragor de elementos de lo "socialmente compartido", de la pertenencia a grupos y otros colectivos, y de lo "individualmente único" (Giménez, 2009).

Sobre la intencionalidad del Procede y su impacto en el campo distinguimos posiciones encontradas. La primera -de menor impacto en el medio académico está a favor del Programa, como es el caso de Zepeda (2000), quien sostiene que el objetivo de esta nueva ley fue dar alternativas, particularmente a los ejidatarios y comuneros, dándoles el poder de elegir entre varias opciones sin diversificar los riesgos y la actividad productiva. La otra en franco cuestionamiento asevera que "(...) con el Procede se ingresa a la lógica mercantil de la propiedad, que prácticamente transforma los usos rurales” (Cruz, 2001: 195).

No estando muy lejos del análisis académico, en esta última estaría la postura del ejido en estudio. 
Con base en Fernández de Rota (1992), afirmamos que la postura de resistencia y defensa de los actores de Ballesteros, no hacen sino explicarnos el gran conocimiento de sus bienes patrimoniales, al igual del resumen que sintetiza el autor:

"son capaces de ver los distintos tamaños de cada serie de árboles, la mayor o menor densidad de sus copas, y distinguir con toda claridad las distintas parcelas [...], saben perfectamente bien cuál es cada uno de sus propietarios, sabe cuándo plantó o cortó árboles y por qué, saben la historia reciente de herencias, particiones, ventas, conflictos. Conocen la historia interna de cada una de ellas. Son ellos los que reconstruyen, transforman, reordenan y contemplan una y otra vez con sentido, el paisaje (su territorio)" (Fernández de Rota, 1992: 393, 399).

Aún más:

"la presencia de masas de vegetación arbórea mantenida por las comunidades como reservas o áreas de manejo agroforestal (...), ofrece un servicio a la nación (y al mundo), porque preservan la diversidad biológica, mantienen los mecanismos de captación de agua (cuencas hidrológicas) y capturan hidróxido de carbono de la atmósfera, contribuyendo así a mantener la salud climática del planeta. Estos servicios (inclusive) deben ser pagados por el gobierno y/o las Naciones Unidas" (Toledo, 2000: 175).

Qué duda cabe, los actores no hacen sino manifestar que la contienda no es un problema o limitación: es una gran oportunidad para sus espacios de aprendizaje en estrategias y formas de permanencia en su histórico patrimonio codiciado por propios y extraños. La reconfiguración de su territorio gestionado por ellos es una de las salidas de fuerza. Nadie más puede acuñar un interés genuino sobre los patrimonios naturales de Ojo de Agua de Ballesteros, que ellos mismos. Scott (2000) llama discurso oculto a esta muestra de identidad por la tierra y el territorio, a este espacio en donde los subordinados de manera sutil se resisten.

Si hacemos un ejercicio comparativo entre Ojo de Agua de Ballesteros y otros ejidos localizados en el ámbito local-regional podremos percatarnos fácilmente de que el caso que aquí se expuso presenta una realidad diferente: hay conservación, preservación, protección, reforestación, vigilancia y relación directa con la tierra. ${ }^{10}$

Imaginemos lo que sucede en otros lugares de nuestro país, en un texto de Sánchez (2011) en el que se narra el testimonio de una mujer campesina, que al regresar a su pueblo luego de haber vivido como migrante, experimenta el impacto causado por la contaminación al agua de su territorio:

"Entonces caminé hacia los árboles y te digo que eso me marcó para toda la vida. Conforme yo iba caminando hacia los árboles y escuchaba más fuerte el agua, yo esperaba ver mucha agua correr, por el ruido que escuchaba y lo que vi fue impactante. Vi un montón de basura que rodeaba los árboles y las raíces. El agua a penas se veía. Había lugares ya pantanosos que olían fuerte. Entre más me acercaba yo ese lodo echado a perder, pantanoso. Esa imagen significó mucho. Hasta el día de hoy sigue causando mucho impacto en mí y por eso hago lo que hago, yo creo. Tuve un sentimiento de coraje, tristeza, indignación.

10 En Ballesteros no existe la renta de la tierra, su gente la trabaja, a diferencia del resto de los ejidos de la localidad y la región en donde las tierras en renta se dispararon a partir de que entraron al proceso de certificación promovido por el PROCEDE. 
Fue una revolución dentro de mí, me quedé sin palabras” (Sánchez, 2011: 81).

En otro acápite, continúa el testimonio:

"Carmen, aquí está el manantial delante. A unos metros de aquí está el manantial. Si quieres vamos. Yo no quiero ir, iyo no quiero saber nada! Sin embargo fui; la verdad fue algo bien, bien fuerte. Recorrimos unos 300 metros río adentro, pero no por las orillas, nos metimos. Empecé a caminar por las piedras y entre más caminaba esa emoción crecía más. Miles y miles de litros de agua, sin que nadie podría disfrutarla porque estaba lleno de basura. Llegué a mi casa y le dije a mi familia: ¡ hay que rescatari. Muy tranquilos me dijeron. Así ha estado por años.

- ¿Porqué no lo limpian? ¿Por qué no le sacan la basura si el agua es limpia? -pregunté yo.

¿Para qué? Ahorita lo limpiamos y mañana está igual” (Sánchez, 2011).

¿Hasta dónde los pueblos deben aceptar vivir en estos territorios transgredidos, desfigurados? Entonces, Ballesteros como actores perseverantes -aunque anónimos- de la sustentabilidad, al enfrentar el asedio de la oficialidad, vienen impidiendo que el territorio y el paisaje campesino empiecen a vivir en el caos, la inmundicia y la hediondez.

\section{Contribuciones a la sustentabilidad desde un contexto local}

La contribución del ejido a la sustentabilidad se manifiesta de manera general en los siguientes elementos.

En primer lugar, contribuye a la preservación y reproducción de la zona ecológica y agroecológica, teniendo como escenario sus principales patrimonios como son bosque, ojos de agua, y tierra adheridos a una gestión de resistencia de sus actores, mediante un aprovechamiento compartido.

En segundo lugar, a través de su interacción con el entorno, permiten la reproducción de un banco de Vida sustentado especialmente en especies propias del lugar.

En tercer lugar, una cultura ecológica y sustentable del ambiente se expresa en el cuidado, preservación, protección, vigilancia y defensa de sus patrimonios, resistiendo el asedio de entidades gubernamentales (especialmente Procede) y el saqueo y amenaza ante la erosión y destrucción de su patrimonio.

En cuarto lugar, contribuye al mantenimiento de la integralidad y calidad de su patrimonio natural, por ello la vigilancia y la vinculación con entidades que instalaron de manera conjunta un cerco alrededor del bosque, asimismo la reforestación comunal en partes eriazas.

En quinto lugar, a través del cuidado del bosque, se promueve también la conservación de la diversidad genética y biológica.

Finalmente, se fomenta la regeneración de especies silvestres, con lo que se resume una historia de protección, y contienda como respuesta a la disputa. Asimismo, se sigue conservando la diversidad agrícola, y produciendo cultivos milenarios (maíz, frijol, cacahuate, nopal, entre otros). Todavía a la fecha, constituye uno de los pocos parajes o territorios del Bajío en donde es posible observar la trilogía o policultivo maíz, frijol y calabaza como parte de un mismo sistema.

\section{Reflexiones finales}

De ser una creación estatal, producto de la Revolución Mexicana, con esquemas de subordinación a las directrices de la política pública y a los organismos públicos y corporativos, 
sujetos a los vaivenes de la dinámica económica del sector, algunos ejidos como el que aquí se abordó en este estudio, transitaron a través de procesos de apropiación individual y colectiva hacia dinámicas propias sustentadas desde la complejidad de la cultura local y articuladas al territorio. Ojo de Agua de Ballesteros constituye un ejemplo de cómo el apego al lugar y el sentido de pertenencia a una cultura, se traducen en identidades sociales vivas, trascendentes.

Es a través de la apropiación como las personas y las colectividades se hacen a sí mismas mediante las propias acciones, en un contexto sociocultural e histórico. Este proceso -cercano al de socialización-, es también el del dominio de las significaciones del objeto o del espacio que es apropiado, independientemente de su propiedad legal (Vidal y Pol, 2005).

La trayectoria y presencia de la gente de Ojo de Agua de Ballesteros en este lugar del Bajío, en pleno Eje Neovolcánico, no se resume sólo como un proceso de adaptación, más bien nos remite al dominio de una aptitud, de la capacidad de apropiación que se expresa de manera concreta, en términos temporales, en actitudes: sobre la gente, el lugar y el ambiente.

El ambiente, y dentro de él el agua como sustrato de vida y cultura, nos remitió a la observación y estudio de la obra de su cauce, al análisis del sistema hidroagrícola del que se sostienen. Esto nos permitió entender y reconocer que un sistema de riego campesino no solamente requiere del estudio de la infraestructura, sino también del estudio y la caracterización de la gestión del agua en este sistema, así como de la historia del manejo social del agua. Nos permitió entender cómo una sociedad que está regando, se organizó y sigue organizándose frente a cambios agroeconómicos eventuales y crisis de saturación del recurso. ${ }^{11}$ De esta manera, el estudio de la evolución histórica de las reglas sociales en las comunidades campesinas, en cuanto al reparto del agua y a su organización, es un elemento fundamental para prever el futuro de estos sistemas (Ruf y Núñez, 1991).

En efecto, la dinámica fundamental de las interacciones entre las sociedades humanas y su entorno natural puede ser expresada idealmente a través de las transformaciones sucesivas que van experimentando los paisajes debido a la intervención de los humanos en sus ecosistemas, y las sociedades responsables de esas transformaciones. Esto nos podría permitir establecer una periodización de los procesos de reorganización del mundo natural y de la organización social, correspondiente a los medios técnicos empleados y los propósitos políticos con que esa transformación del mundo natural ha sido llevada a cabo. ${ }^{12}$

Desde una perspectiva histórica, los paisajes resultantes de esa actividad expresan las consecuencias ambientales de la explotación de un mismo territorio a partir de percepciones culturalmente distintas de la naturaleza, asociadas a intereses económicos y políticos diferentes.

Un aspecto latente, y que es fundamental en esta investigación y de este tipo de estudios, es no perder de vista y reconocer la cuestión de la exclusión o la inclusión de personas y grupos dentro de la propuesta a futuro de un territorio, ya que su consideración constituye un elemento clave en la forma de generar significados y vínculos con los entornos.

Los conceptos que aquí se propusieron en este estudio y que han sido explicados desde la apropiación del espacio, constituyen una propuesta que ha sido parcialmente contrastada de manera empírica. Con esto queremos plantear que la apropiación del espacio constituye una propuesta teórica para abordar la agenda social y el diseño de los espacios rurales.

\footnotetext{
11 En el ejido existe un manejo comunitario del agua basado en normas de apropiación colectiva que incluye pocos casos de manejo individual. El sistema abarca el manejo superficial y subterráneo del agua y un caso particular de aguas termales que son utilizadas para diversos fines, en especial para la provisión de agua de un balnerario ejidal representativo en la zona. Para conocer algunos detalles del sistema, ver: Mazabel et al (2013). 12 Para el geógrafo francés Pierre Gourou (1984: Cap. I), por ejemplo, cada paisaje constituye una síntesis de las "técnicas de producción" y "las técnicas de encuadramiento" de la sociedad que lo ha creado, sobredeterminada a menudo, además, por los "paisajes fósiles" legados por las sociedades precedentes.
} 


\section{Agradecimientos}

A todos los pobladores de Ojo de Agua de Ballesteros por todo su tiempo, gran interés y abierta disposición. De manera particular a los estudiantes de la Licenciatura en Desarrollo Regional, quienes constituyen nuestro Semillero de Investigación en la Universidad de Guanajuato: María Cristina Maldonado Jiménez y Miriam Mónica Torres López, quienes en calidad de becarias de investigación participaron decisivamente en el trabajo; asimismo, a Cristina Rentería Gallardo, Luis Eduardo Verdín, José Francisco López, Andrea Cristina Maldonado Lira y Luz Andrea Novoa, quienes como estudiantes de la Práctica de Diagnóstico realizaron un acercamiento a la realidad de Ojo de Agua de Ballesteros.

\section{Bibliografía}

ALEJO, Miguel, (2010) Historia y evolución de Salvatierra. México, Comisión Estatal para la Organización de la Conmemoración del Bicentenario del inicio del Movimiento de Independencia Nacional y del Centenario del inicio de la Revolución Mexicana.

ALTMAN, Irwin, (1975) The environment and social behavior: Privacy, personal space, territoriality and crowding. Monterrey (Ca.): Brooks/Cole.

BARTOLOMÉ, Miguel Ángel, (1997) Gente de costumbre y gente de razón. Las identidades étnicas en México. México, Siglo XXI Editores/INI.

BROWER, Sidney, (1980) "Territory in Urban Settings" en I. Altman, A. Rapoport y J.F. Wohlwill (Eds.), Culture and Environment. Human Behavior and Environment (vol. 4, pp. 179207). New York: Plenum Press.

CONCHEIRO, Luciano, (1995) "Conceptualización del mercado de tierras: una perspectiva campesina" en FAO, Mercado de tierras en México. Roma, UAM-X-Organización de las Naciones Unidas para la Agricultura y Alimentación (FAO), 160-175.

CRUZ, María Soledad, (2001) Propiedad, poblamiento y periferia rural en la Ciudad de México, México, Red Nacional de Investigación Urbana / UAM-A. CRUZ, María Soledad, (2001) Propiedad, poblamiento y periferia rural en la Ciudad de México, México, Red Nacional de Investigación Urbana / UAM-A.

DURKHEIM, Emile, (1998a) El Suicidio. Buenos Aires, Grupo Editorial Tomo, Primera edición.

DURKHEIM, Emile, (1998b) La División del Trabajo Social. Ciudad de México, Editorial Colofón, Primera edición.

FERNÁNDEZ DE ROTA, José Antonio., (1992) “Antropología simbólica del paisaje” en La tierra, mitos, ritosy realidades. Barcelona, España, Diputación Provincial de Granada / Anthropos.

FRACCHIA, Myriam, (1997) Procesos constitutivos de una nueva identidad social en los distritos de riego: la mujer productora y jefa multiempresarial de familias transnacionalizadas. Tesis de maestría en Desarrollo Rural, México, UAM-Xochimilco.

FOUCAULT, Michel (1998) [1975], Vigilar y Castigar, México, Siglo XXI.

GOUROU, Pierre, (1984) Introducción a la geografía humana. Madrid, España, Alianza.

GIMÉNEZ, Gilberto, (2009) "Cultura, identidad y memoria. Materiales para una sociología de los procesos culturales en las franjas fronterizas" en Frontera Norte, vol. 21, núm. 41 México, jan./jun.

LÉVI-STRAUSS, Claude, (1992) El pensamiento salvaje. 7a. reimpresión, México, FCE.

MAZABEL, Davison; VALDÉS, Alberto; MOSQUEDA, Eloy, (2013) Estudios Culturales, Demográficos y Políticos. México, Editorial Altrés - Costa Amic / Universidad de Guanajuato. Pp. 195-239.

MELUCCI, Alberto, (1999) Acción Colectiva, vida cotidiana y democracia. México, El Colegio de México.

POL, Enric, (1996) "La apropiación del espacio” en L. Íñiguez y E. Pol (Eds.), Cognición, representación y apropiación del espacio. Barcelona, Collecció Monografies Psico-Socio-Ambientals (vol. 9, pp. 45-62). Publicacions de la Universitat de Barcelona. (Original, 1994, en Familia y Sociedad, 12, 233-249). 
POL, Enric, (1997) “Symbolism a priori. Symbolism a posteriori” en A. Remesar (Ed.) Urban regeneration. A challenge for public art. Collecció Monografies Psico/Socio/Ambientals (vol. 6, pp.71-76). Barcelona: Publicacions de la Universitat de Barcelona.

POL, Enric, (2002a) "El modelo dual de la apropiación del espacio" en R.García Mira, J.M. Sabucedo y J.Romay (Eds.), Psicología y Medio Ambiente. Aspectos psicosociales, educativos y metodológicos. (pp.123-132). A Coruña: Asociación galega de estudios e investigación psicosocial.

POL, Enric; MORENO, Emilia; GUARDIA, Joan \& Lupicinio ÍÑIGUEZ, (2002b) "City-IdentitySustainability Network Structural Model Identity, Quality of Life, and Sustainability in an Urban Suburb of Barcelona" en Environment and Behavior, 34(1), p. 67-80.

RUF Thierry. y Pablo NÚÑEZ, (1991) "Enfoque histórico del riego tradicional en los Andes del Ecuador" en Memoria, año 2, núm. 2, Quito, Instituto de Historia y Antropología Andina Marka.

SACK, Robert, (1991) "El significado de la territorialidad" en P. Pérez Herrero (comp.) Región e historia en México (1700-1850). México, Instituto Mora/Universidad Autónoma Metropolitana.

SÁNCHEZ, Víctor Hugo, (2011) “Jiutepec: de la Caña de azúcar a la urbanización salvaje. La emergencia de nuevos actores sociales" en Mundos Rurales, núm. 02. México, Universidad Autónoma Metropolitana, Unidad Xochimilco, Posgrado en Desarrollo Rural.

SCOTT, James, (2000) Los Dominados y el Arte de la Resistencia. México, ERA.

SECRETARÍA DE LA REFORMA AGRARIA, Procuraduría Agraria, INEGI, Registro Agrario Nacional (2006) Informe de Rendición de Cuentas 2000-2006, Libro Blanco, PROCEDE http://www.sra.gob.mx/sraweb/datastore/transparencia/rendicion/LibroBlancoProcede. pdf (Fecha de consulta: 14/04/2013).

TOLEDO, Víctor, (2000) La paz en Chiapas, ecología, luchas indígenas y modernidad alternativa. México, Instituto de Ecología-UNAM / Quinto Sol.

VIDAL, Tomeu y Enric POL, (2005) "La apropiación del espacio: una propuesta teórica para comprender la vinculación entre las personas y los lugares" en Anuario de Psicología, vol. 36, no 3, 281-297.

ZEPEDA, Guillermo, (2000) Transformación Agraria. Los Derechos de propiedad en el campo mexicano bajo el nuevo marco institucional. México, CIDAC, Porrúa. 